\title{
EXPLORING THE USE OF AGENT-BASED MODELING (ABM) IN MIXED METHODS RESEARCH
}

\author{
EXPLORANDO EL USO DEL MODELO BASADO EN AGENTES (MBA) EN \\ INVESTIGACIONES CON MÉTODOS MIXTOS
}

\author{
Henrik Skaug Sætra \\ Østfold University College, Halden. Noruega/Norway \\ henrik.satra@hiof.no
}

Recibido/Received: 11/05/2017

Modificado/Modified: 26/07/2017

Aceptado/Accepted: 29/9/2017

\begin{abstract}
Agent-based modeling (ABM) is in many ways an outsider in social research methods, but I will here argue that it has an important role to play in combination with other methods and approaches. ABM can be used in ways that offer unique benefits to social science researchers, but due to the abstract nature of the gained insights, this requires the employment of various methodologies in combination with ABM. Mixed methods (MM) is an approach that has become quite popular, and I show that even if $\mathrm{ABM}$ naturally may seem like a natural ingredient in research where methods are mixed, there exists some peculiarities within MM that may make it less accommodating to ABM that one may assume.
\end{abstract}

\section{KEYWORDS}

Agent-based modeling; mixed methods; triangulation; multi method research; social research methods.

\section{CONTENTS}

1. Introduction. 2. Mixed methods, multi method research or triangulation. 2.1. The problem of integration. 3. Agent-based modeling. 3.1. Induction or deduction - quantitative or qualitative? 3.2. Emergence, methodological individualism and holism. 4. Simulation and empirical data. 4.1. Theoretical generalization. 5. Employing ABM in mixed methods research. 6. Conclusion. References.

\section{RESUMEN}

Los modelos basados en agentes (MBA) son, en muchos sentidos, métodos poco utilizados en la investigación social pero, en el presente artículo, se tratará de demostrar que pueden jugar un papel importante en combinación con otros métodos y enfoques. Los MBA pueden ser utilizados en modos que aportan unos beneficios excepcionales a los investigadores de las ciencias sociales si bien, dada la naturaleza abstracta de las diferentes perspectivas que se obtienen, esto requiere el uso de varias metodologías en combinación con los MBA. Los métodos mixtos (MM) son una estrategia de investigación que se ha hecho muy popular y aquí se muestra que, incluso siendo vistos los MBA como un ingrediente natural en las investigaciones en las que se utilizan varios métodos, se dan una serie de peculiaridades, dentro de los mismos MM, que los hacen menos acomodaticios a los MBA de lo que se podría presumir en un primer momento. 


\section{PALABRAS CLAVE}

Modelo basado en agentes; métodos mixtos; triangulación; investigación multi-método; métodos de investigación social.

\section{SUMARIO}

1. Introducción. 2. Métodos mixtos, investigación multimétodo o triangulación. 2.1. El problema de la integración. 3. Modelos basados en agentes (MBA). 3.1. Inducción o deducción - cuantitativo o cualitativo? 3.2. Surgimiento, individualismo metodológico y holismo. 4. Simulación y datos empíricos. 4.1. Generalización teórica. 5. Utilizando los métodos de investigación mixtos MBA. Conclusiones. Bibliografía.

\section{INTRODUCTION}

Agent-based modeling (ABM) is a fairly new method in the social sciences, and in this paper I'll discuss the possible use of ABM in mixed methods research. Much literature on mixed methods focus on the mix of traditional empirical approaches easily labeled as quantitative or qualitative. ABM is somewhat hard to place in these traditional categories, so I'll examine how we can categorize ABM differently and combine it with other methods.

The main reason for using $\mathrm{ABM}$ in social science is the possibility of examining emergence and social mechanisms. These phenomena can be difficult to research with traditional social science methods, which is why I argue that we can reap benefits from increased use of $\mathrm{ABM}$. The main drawback of $\mathrm{ABM}$ is often held to be its remoteness from the real phenomena we are interested in, which is why I argue that it must be combined with other approaches in order to evaluate the validity of the findings of this kind of research.

\section{MIXED METHODS, MULTI METHOD RESEARCH OR TRIANGULATION}

Mixed methods are, in broad terms, an attempt to utilize several methods in our research. As a methodology it "involves philosophical assumptions that guide the direction of the collection and analysis and the mixture of qualitative and quantitative approaches in many phases of the research process", while as a method "it focuses on collecting, analyzing, and mixing both quantitative and qualitative data in a single study or series of studies" (Creswell 2011:271). The rationale for mixed methods is the idea that the combination of approaches "provides a better understanding of research problems than either approach alone" (Creswell 2011:271,280). Johnson et al. (2007:112) regards the definition of mixed methods as problematic, and since "there might not be a perfect or essentialist definition forthcoming", they seek dialogue and "social construction" of "workable definitions" and connect their position with the pragmatist philosophy of Dewey and others (Johnson et al. 2007:112). They do, however, offer a general definition, and say that it is a "type of research in which a researcher or team of researchers combines elements of qualitative and quantitative research approaches (e.g., use of qualitative and quantitative viewpoints, data collection, analysis, inference techniques) for the broad purposes of breadth and depth of understand and corroboration (Johnson et al. 2007:123). As many proponents of mixed methods links it explicitly to the mix of quantitative and qualitative research, the difficulty of categorizing ABM may cause problems with the labeling of research involving this method. This topic is discussed in 3.1. Whether or not mixed methods is something new (some call it a "third 
paradigm"), or simply the re-wrapping of older ideas is beyond the scope of this article; see for example Creswell (2011:273) for a discussion of this issue (Johnson et al. 2007:112; Johnson and Onwuegbuzie 2004:14).

Beyond mixing quantitative and qualitative research, my usage of the term mixed methods draws upon the call of Bryman (2007) to genuinely integrate methods; this would come about by combining various methods in "mutually illuminating" ways through analysis, interpretation and the writing up of research (Bryman 2007:8). In practice, this demands that the "end product is more than the sum of the individual quantitative and qualitative parts" (Bryman 2007:8). I focus mostly on how ABM can be used to discover, develop and test theories and support mixed methods research in the quest for analytical generalization (see 4.1). As such, this paper is somewhat disconnected from the more practical parts of the literature on mixed methods, where the issues of combining qualitative and quantitative research is often the main topic.

The relationship between the quantitative and the qualitative parts of mixed methods research has been thoroughly developed in various typologies and frameworks, which I'll only briefly summarize here. Creswell and Plano Clark (2011) deals with mixed methods research designs, and points to the typologies of Greene et al. (1989) and Bryman (2006). Creswell and Plano Clark (2011) then propose 4 basic mixed methods designs: convergentparallel design, explanatory sequential design, exploratory sequential design and the embedded design; in addition, they mention the transformative design and the multiphase design (Creswell and Plano Clark 2011:69). Of main importance is the four questions: "whether the strands will remain independent or be interactive; whether the two strands will have equal or unequal priority for addressing the study's purpose; whether the strands will be implemented concurrently, sequentially, or across multiple phases; and how the strands are to be mixed" (Creswell and Plano Clark 2011:105). Viewing the combination of ABM with other methods as a specialized design might be a good approach, due to the problems of categorizing ABM (Johnson et al. 2007:128). Teddlie and Tashakkori (2006) offer another typology that is widely referred to, offering four basic "families" of designs: "sequential, concurrent, conversion, and fully integrated" (Teddlie and Tashakkori 2006:25).

Heyvaert et al. (2013) proposes a typology for mixing methods at the synthesis level, and gives a classification framework with 18 possible designs. This is portrayed by using capital or lowercase letters (capital letters indicating a dominating status) and + or $\rightarrow$ to separate the designs ( + indicating a concurrent and $\rightarrow$ a sequential approach). In addition, the first approach is denoted by $A$ - or $S$-, where A indicates that all of the data of that kind is involved in all stages of the research, while $\mathrm{S}$ indicates that only some of it is. Thus, " $A-$ $Q U A L+q u a n$ " would indicate a study where the qualitative strand was dominant, all parts of the qualitative data was used in the entire study, and the two strands were conducted concurrently. " $S$-quan $\rightarrow Q U A L$ " indicates a study where a quantitative study was carried out first, and some of the data from that study is carried over to the following parts, where a qualitative approach dominates. Leech and Onwuegbuzie (2009) put forth a similar typology with 8 possible designs using the same notation, without the $A$ 's and $S$ 's employed by Heyvaert et al. (2013).

\subsection{The problem of integration}

Bryman lists 9 barriers to the integration of different methods:

1. Different audiences; 2. Methodological preferences; 3. Structure of research projects; 4. Role of timelines; 5. Skill specialisms; 6. Nature of the data; 7. Bridging ontological divides; 8. Publication issues; 9. Problems of exemplars (Bryman 


\section{7:12-19)}

Many of these barriers touch upon the same issues, namely that both researchers and various audiences are most familiar with one form of research, and implementing the less familiar kinds brings problems in terms of understanding and cooperation, funding and publication, as well as the practical difficulties of actually combining research of different natures.

One interesting barrier is the "ontological divide", where Bryman (2007:16) refers to problems of "marrying an objectivist account with a constructivist one". The ontological barrier is most often addressed by adhering to a pragmatist philosophy (Bryman 2007:17). According to Johnson et al. (2007:113), the "primary philosophy of mixed research is that of pragmatism", and the pluralism of "viewpoints, perspectives, positions and standpoints" is claimed to be the reason for this; it is also claimed to offer "epistemological justification (i.e., via pragmatic epistemic values or standards) and logic (i.e., use the combination of methods and ideas that helps one best frame, address, and provide tentative answers to ones' research question[s]) for mixing approaches and methods" (Johnson et al. 2007:125). Morgan (2007) also advocates pragmatism as a good basis for mixed methods, while Johnson et al. (2007:129) explicitly states that mixed methods is research that "partners with the philosophy of pragmatism" - a view I do not endorse.

The fact that ontological issues are problematic in mixed methods research has led to a focus on practical issues rather than philosophical ones. Throughout the paper I will refer to the possibility of basing mixed methods and ABM research on the critical realist (CR) philosophy, but this possibility cannot be fully pursued due to space constraints. Miller (2014) has proposed "critical realism as a philosophical perspective to understand and orient agent-based modeling research"; he sees critical realism as supporting the ABM approach, due to CR's "mechanistic explanations, emergence, simplifying assumptions, and abductive reasoning"; further, $\mathrm{CR}$ can help $\mathrm{ABM}$ practitioners in "clarifying ontology, evaluating model outcomes, validating models, triangulating, and identifying the limits of agent-based modeling" (Miller 2014:175).

The problem of exemplars - lack of authoritative exemplar studies - will perhaps be even stronger when one attempts to employ ABM in mixed methods, as this has not been done much previously. An important step is thus to show how it can be done, and then actual research following these strategies will have to be carried out. I argue that the barriers listed above is caused in part by the lack of a proper philosophy of science capable of uniting different methods, and until this can be found, exemplars will be hard to come by. If mixed methods is indeed some "emancipatory" haven where all "legitimate" methods are welcome, catering to the pragmatist "philosophy of free choice", moving forward may indeed be hard (Symonds and Gorard 2008:3).

Whereas triangulation is often portrayed as an important form of mixed methods research, Bryman (2007:17) sees this concept as a possible limitation for genuine integration. Mixed methods should perhaps be more about integrating the different methods than about seeing whether or not they corroborate each other - an endeavor that does not require true mixing. Triangulation can involve a) data triangulation, b) investigator triangulation, c) theory triangulation or d) methodological triangulation (Johnson et al. 2007:114). The possible outcomes of triangulation are "convergence, inconsistency, and contradiction" (Johnson et al. 2007:115). These aspects of triangulation are obviously of great importance in the mixing of ABM with other methods, but the simplest design where two methods are used separately and the answers simply compared does not qualify for what I refer here to as "mixed" methods. 


\section{AGENT-BASED MODELING}

Computer simulation started with the entrance of computers in universities in the 1960's (Gilbert and Troitzsch 2005:6). Since then, computing power and general accessibility has led to great advances in simulation, and in the 1990's we saw the birth of multi agent models, which gave rise to the particular form of simulation I here focus on: agent-based modeling (Gilbert and Troitzsch 2005:8). ABM is characterized by many (potentially) highly complex agents; according to Railsback and Grimm (2011:xii-xiii) the "multi-agent systems" discussed by Gilbert and Troitzsch (2005:13) is a branch of ABM that "originated from computer science and research on artificial intelligence and artificial life".

Agent-based modeling is also referred to as individual-based modeling, particularly in the field of ecology (Railsback and Grimm 2011:xi). The name of the approach is quite descriptive of what it really is: an approach where individual agents are modeled, instead of modeling systems with variables of their own (as was done by the Club of Rome for example) (Gilbert and Troitzsch 2005:6; Railsback and Grimm 2011:10). The "agents" may, however, be "organisms, humans, businesses, institutions, and any other entity that pursues a certain goal" (Railsback and Grimm 2011:10). ABM is thus not necessarily committed to methodological individualism, but I will here focus mostly on the strains of ABM that are. Methodological individualism is discussed in more detail in 3.2.

So, why do (or should) we model? Some mechanisms are hard to discover or observe directly, and simulation may help us understand these underlying processes (Gilbert and Troitzsch 2005:4). If our theories, turned into models, correspond to the real world, we may use our simulations to predict future developments (Gilbert and Troitzsch 2005:4). If we have established the realism of our model, we can also run sensitivity analyses, which can be very useful (Gilbert and Troitzsch 2005:24).

Another reason, and perhaps the most important one for social scientists, is the assistance simulation can give us in discovery and formalization. "Social scientists can build very simple models that focus on some small aspect of the social world and discover the consequences of their theories in the 'artificial society' that they have built. In order to do this they need to take theories that have conventionally been expressed in textual form, and to formalize them into a specification which can be programmed into a computer" (Gilbert and Troitzsch 2005:5). One great example of discovery and formalization can be found in The Evolution of Cooperation (Axelrod 2006b), where the conditions for and forms of cooperation is examined through, amongst other approaches, a "tournament" of various agents in an ABM; the theme is further developed in The Complexity of cooperation (Axelrod 2006a).

Yet another potential use for $\mathrm{ABM}$ is the possibility of experimenting with utopias and counterfactuals. New worlds and new ways of interacting and organizing communities may easily be developed, and the findings may at times have interesting implications (Gilbert and Troitzsch 2005:26). This application of ABM is perhaps most interesting for those involved in "transformative-emancipatory" research (Creswell 2011:276; Teddlie and Tashakkori 2006:13-4; Creswell and Plano Clark 2011:69,96-100). With regards to critical realism, it also has an emancipatory dimension that may be of interest for all practitioners of ABM, regardless of the kinds of worlds they model (Archer 1998:199; Bhaskar 1998b:207,235; Bhaskar 1998a; Bhaskar 2009; Collier 1998; Outhwaite 1998:315).

\subsection{Induction or deduction - quantitative or qualitative?}

$\mathrm{ABM}$ can be employed in both inductive and deductive enterprises, and is in no way 
restricted to or "belong" to one approach. I may have a theory and decide to make a model and run simulations in order to test it, in which case I'm following the deductive approach. Gilbert and Troitzsch (2005:15) describes how the analytical method is often the foundation of our models, where we reason and employ mathematics and logic in order to develop our models for testing. Winsberg $(2003: 116)$ at times seems to assume the deductive use of simulation, in that he describes it as "a technique that begins with well-established theoretical principles, and through a carefully crafted process, creates new descriptions of the systems governed by those principles".

While some say induction requires going into a situation as tabula rasa, this would of course preclude induction in $\mathrm{ABM}$; in order to make a model I must make explicit some assumptions about what sort of actors I want to model and what characteristics I want them to have. I will, however, consider the approach of making models "blindly" and introducing various variables and factors in the environment, without any clear expectations of what will happen, an inductive approach. Here is another difference between mathematics and ABM: while making mathematical equations requires pretty clear ideas about our theories in order to make models, many models resulting from ABM are the results of pure "play", or trialand-error (Winsberg 2003:109). Tinkering with various variables, ways of interacting, and factors of the environment is one of the most rewarding aspects of working with ABM, and this exploratory, or inductive, activity must not be downplayed.

The exploratory use of ABM is by some called a "third possibility, in which one starts out from a set of assumptions, but then uses an experimental method to generate data which can be analyzed inductively (Axelrod 2003:5; Gilbert and Troitzsch 2005:26). Whether you call this something different than induction and deduction in cycles may not be of that great importance. In critical realism, the central form of inference is held to be retroduction, which, instead of seeking generalizations, seeks to "identify a factor responsible", letting us formulate theories of mechanisms which may explain observed phenomena (Lawson 1998:156). Miller (2014:181) claims that doing ABM is mainly about abductive reasoning inferring "antecedent causes from consequents" and forming hypothesis for testing. The term "abductive" stems from Peirce (1992) and "starts from facts" without theory, but, in contrast to induction, where one search for facts, with abduction one seeks a theory Peirce (1998:106). "Abductive reasoning" is by many seen as the same as "retroduction": examining some "unexplained phenomena and propose hypothetical mechanisms that, if they existed, would generate or cause that which is to be explained" (Mingers 2006:23). Morgan (2007:63) uses the term "abductive" for the reasoning that "moves back and forth between induction and deduction", and connects this to the pragmatist philosophy, which we have seen is often used as the basis for mixed methods. Yet another proposal is given by Epstein and Axtell (1996:176), who sees generative social science as a fruitful label, as what ABM is about is "clearly not inductive or deductive"; they like "generative", due to the endeavor to generate social phenomena by microspecifications (agents, environment and rules). Regarding simulation as a "third mode" of science, between theory and the experiment, is discussed in detail by Winsberg (2003:117), and also Axelrod (2003).

Is $\mathrm{ABM}$ a quantitative or a qualitative undertaking? While there are numbers created in the process of running simulations, it may be argued that much of what goes on in the creation of models, and the interpretation of them, is in fact qualitative. The case may be argued, however, that the labels of quantitative and qualitative are ill suited for a phenomenon not directly connected to some form of empirical data. Some regard simulations as "little more than stuff of our minds" or "figment[s] of our imagination" (Crookall 2011:146,148). 
Gobo (2008a) has called for a move beyond the categories of quantitative and qualitative, and his alternative classification is defined by six cognitive modes:

1. listening; 2. questioning; 3. observing; 4. reading; 5 . operating: .i.e. seeking to change actors (putting them to the test, having them interact with each other or stimulating them in order to control their reactions); and 6. introspection/reflecting

(Gobo 2008a:23).

If simulations are merely figments of our imagination, then doing ABM involves the cognitive modes of introspection and reflection in order to gain insight into social phenomena; this is linked to phenomenological research with "individual experience" from amongst other sources thought-experiments as the method of data collection (Gobo 2008a:25-7). Gobo (2008a:26) explicitly mentions experiments and simulations under the transformative methodology with an operative cognitive mode, but here links it explicitly to research that not "only aims to acquire knowledge". Since simulations do not involve real actors, there is a clear difference between simulation and traditional experiments. There are also obvious similarities, so placing ABM firmly in this alternative classification is perhaps not that much simpler than in the conventional classification. If we do label ABM a transformative methodology, we must take care to separate it clearly from various forms of action research etc. involving seeking change in the phenomenon examined. Simulations do not necessarily have either the intent to reform or the effects on the real phenomenon being investigated that characterize other approaches labeled transformative.

\subsection{Emergence, methodological individualism and holism}

Emergence is often seen as the key to understanding the relationship between the individual and social phenomena. Gilbert and Troitzsch (2005:11) illustrates this with Durkheims claim that "social phenomena are external to individuals" and methodological individualists" outright denial of "society". Could it really be that emergence could be the key to understanding this conflict? If so, $\mathrm{ABM}$ is a promising tool for the purpose.

Railsback and Grimm (2011:10) explains emergence as the "system dynamics that arise from how the system's individual components interact with and respond to each other and their environment". Goldstein (1999:49) defines emergence as "the arising of novel and coherent structures, patterns, and properties during the process of self-organization in complex systems". According to Gilbert and Troitzsch (2005), emergence is the process in which new objects arise at higher levels, due to interactions at a lower level; these new objects must require "new categories" of description, that is not a (necessary) part of the description of lower level agents (Gilbert and Troitzsch 2005:11). They use temperature as an example, as atoms have no temperature, but motions and interactions of atoms together creates this emergent phenomenon (Gilbert and Troitzsch 2005:11) . The emergence of temperature from the temperature-less atoms is, however, somewhat different from emergence of social phenomena; one of the defining aspects of humans are their reflexivity, which gives rise to what some label "second-order emergence" (Gilbert and Troitzsch 2005:11). Levin (1998) uses ecosystems as "prototypical examples" of the complex adaptive systems I'm here talking about. These are characterized by non-linearity which causes "historical dependency and multiple possible outcomes of dynamics" in addition to emergence on higher levels from interactions and mechanisms at lower levels (Levin 1998:431).

The main reason for ABMs usefulness in studying emergence is that they are multi-level, or "across-level", models; in contrast to many other approaches, where you either look at the individual or the system, with ABMs we can go back and forth between the two (or more) 
levels of individuals and system, and we can examine the dynamics that occur between these levels (Railsback and Grimm 2011:10).

Sawyer (2004) argues for the ontological reality of "social properties", and states "that once social properties emerge, they have an ontological status distinct from their realizing mechanisms and may participate in causal relations"; he bases his argument on an "emergentist, systemist, and mechanist approach" (Sawyer 2004:261). One way of arguing the reality of emergent phenomena is attributing causal powers to these phenomena (Goldstein 1999:60; Davidsen 2010:76). Sawyer (2004) and Miller (2014) argue that multi agent systems simulation is the best approach for studying complex phenomena with emergent properties (Sawyer 2004:262; Miller 2014:179). ABM is held to be "a study of how social properties emerge from individual action" (Sawyer 2004:265). Sawyer (2004:266) is not content with the pure reductionist account of emergence, and argues "that although only individuals exist, collectives possess emergent properties that are irreducibly complex and thus cannot be reduced to individual properties"; in this he also refers to critical realism.

Contrary to this view, others point to emergence as a provisional construct - only necessary because we do not yet have the ability to explain macro level phenomena by the micro level agents and interactions (Goldstein 1999:59). In this respect, ABM can appear to be one way of explaining away emergence; by showing how emergent phenomena or social properties once thought to be "real" are in fact reducible to individual actions and motivations, the emergent phenomena loses its "emergency"? Axelrod (2006a:4) touches upon this, when dealing with the possibility of formally deducing some emergent phenomena, but he states that this does not apply to those arising from adaptive (rather than optimizing) strategies. One of the unique advantages of ABM is the chance of discovering what we did not expect, and this is also related to the issue of the unpredictability of emergent phenomena; these issues fall beyond the scope of this article, but more can be read in Goldstein (1999:60) (Gilbert and Troitzsch 2005:10). The charges of provisionality are connected to "ontological-level monism", a metaphysical assumption that "there is only one basic ontological level and the aim of scientific explanation is to reduce all apparently new levels to this primordial level" (Goldstein 1999:61). Critical realism proposes a metaphysic of a stratified reality, where we go from a basic physical level, "to strata of chemistry, biology, psychology and society" (Davidsen 2010:76). Critical realists are thus open for the radical novelty of emergent phenomena at various levels, in a way the ontological level monists are not (Goldstein 1999:61).

Methodological individualism (MI) is clearly implicit in much of the ABM based research done in social science. However, ABM is a multi-level approach that acknowledges emergence and the effects of structure on individual action. ABM thus accommodates complexity theory and the view that "even if we were to have a complete understanding of the factors affecting individual action, this would still not be sufficient to predict group or institutional behavior" (Gilbert and Troitzsch 2005:10). This is due to the complexity of the phenomena we examine, the emergent properties, and the inevitably long causal chains involved (Sawyer 2004:270).

Sawyer (2004:266-7) argues for a "midway" position between MI and holism, in that individualists are wrong to ignore the independent power of emergent social properties, while holists are wrong to ignore individuals and the micro level. I here refer to the "strong" holist claim that systems cannot be explained simply by aggregating the parts, a view that "postulates new system properties and relations among subsystems that had no place in the system components; hence it calls for emergence, a 'creative' principle" that is contrary to 
mechanistic explanations (Simon 1996:171). One purpose of employing mixed methods is to correct the "holistic fallacy" - "to perceive all aspects of a social situation as congruent" that may arise from some qualitative approaches (Sieber 1973:1354).

ABM can perhaps give "life" to methodological individualism, which in its mathematical portrayal in much of political science and economics is rather "dead" and incapable of explaining emergent properties. When there are properties of the whole that can't be explained purely by the individual's motivations and characteristics, ABM has proven to be useful in fostering understanding of the way interactions brings forth these properties.

\section{SIMULATION AND EMPIRICAL DATA}

Little has been written on the use of ABM in mixed methods research. However, the need for empirical work in order to discover to what degree our models correspond with reality is usually accepted. Winsberg (2003:115) quotes Hughes (1999) on the need for an "extra step" in order to know whether or not we are really finding out about "real worlds" with our simulations. According to Hughes (1999:142), "[1]acking other data, we can never evaluate the information that these experiments provide".

Henrickson and McKelvey (2002:7295) make the strong claim that "[a]gent-based modeling should emerge as the preferred modeling approach", and that when combined with "subsequent empirical corroboration" this will lead to important contributions to social science. Miller (2014:187) is another that discusses triangulation and the combination of $\mathrm{ABM}$ and various empirical models in order to address validity issues. One example would be to compare theoretical expectations, simulation data and historical records (Miller 2014:187). Modelers should, as far as possible, present their results in ways that promote easy translation to empirical scenarios (Miller 2014:187). Gilbert and Troitzsch (2005:23) also encourage the comparison of output from our models with data gathered from the real target, as shown in figure 1.

Figure 1: "The logic of simulation", according to Gilbert and Troitzsch (2005:17)

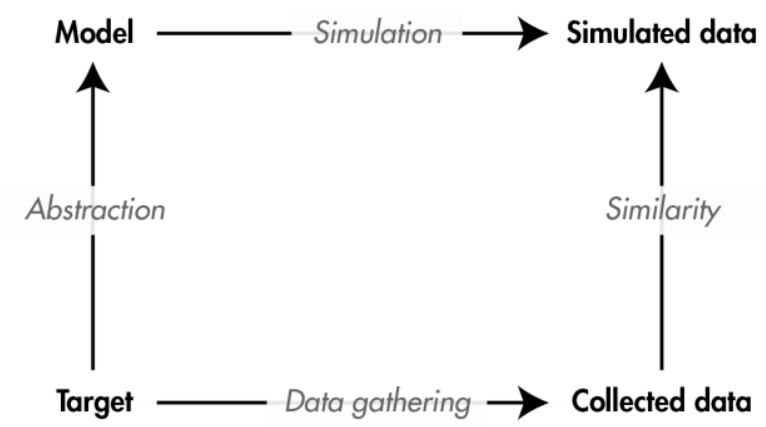

This view of validity could be held to be instrumental, as the "reflected behavior" is what gives validity and the correspondence of final output from the model and the real target (Gilbert and Troitzsch 2005:23). This is, however, not necessarily a problem, if we follow the critical realists who hold that the actual mechanisms are unobservable, which means we'll have to resort to measuring behavior and correlations while arguing for the mechanisms and 
processes we assume to be causing the observed results. Gilbert and Troitzsch (2005:23) mirrors a concern of critical realists in that target processes and our models are likely stochastic, meaning "exact correspondence would therefore not be expected on every occasion". This is part of the nature of systems that are complex and nonlinear, and also open. Path dependency is another factor preventing exact predictions (Gilbert and Troitzsch 2005:23; Levin 1998:433). A high level of abstraction might make the use of ABM in mixed methods research difficult, as the model becomes far removed from the target phenomenon (Gilbert and Troitzsch 2005:23-4). A final interesting remark from Gilbert and Troitzsch (2005:23) is that when our results are not congruent with empirical observations, this may be caused by incorrect data from the real phenomenon. Since the real level is unobservable, our model may in fact be correct but our attempts at empirical verification flawed.

One example of the mix of ABM and other sources of data is found in the article "Understanding Anasazi Culture Change Through Agent-Based Modeling" (Dean et al. 2000). Here they employ the Sugerscape model developed by Epstein and Axtell (1996) in combination with anthropological data, in order to understand the culture of a civilization long gone. Using archeological data from anthropological research they attempt to "recreate - and hence, explain" the spatiotemporal history of the Kayenta Anasazi (Dean et al. 2000). Another example is provided by Axelrod (2006b), who uses historical data from trench warfare in World War I in order to explain the findings from the computer tournament that made the tit-for-tat strategy famous.

\subsection{Theoretical generalization}

By mixing methods as I here propose, we are using data not suitable for statistical generalization, and I argue that this kind of research must focus on theoretical generalization (also referred to as "analytic induction" or "analytic generalization") - a process that involves "identification of the essential characteristics of the phenomenon studied" (Gobo 2008b:195; Onwuegbuzie and Collins 2007:283). If we follow critical realists in focusing on contrastive and underlying mechanisms, the abandonment of statistical generalization is not a loss, as theoretical generalization is the most suitable way of achieving our ends. See Gobo (2008b) for an elaborate account of generalization in his "re-conceptualization" of the concept. As I will not go into detail on the empirical aspects of mixed methods research, sampling problems etc. will not be discussed here; Onwuegbuzie and Collins (2007) goes into detail on the issues of sampling in mixed methods, and Lieberson (1991) has given a good account of the kinds of reasoning applicable to small-N studies.

Williams (2000) discusses moderatum generalizations and "analytic induction", where the latter is seen as some iterative procedure where hypotheses are tested on single or few cases until our theory is either falsified or "until the point is reached when further study will tell us nothing new" (Williams 2000:217). This rather empirical form of analytic induction is not what I refer to as theoretical generalization. He then discusses the claim that one can make theoretical inferences of general laws from a limited number of cases, a view he describes as "rarely upheld in social science these days and increasingly less so in the natural sciences", but one I here partly advocate (Williams 2000:219)

Halkier (2011) deals with "analytical generalization", and divides this approach into three ways of generalizing, of which the following two is of particular interest in this context (I regard the third, positioning, as less relevant to the approach here drafted): ideal types and category zooming. The ideal types of Max Weber is interesting with respects to ABM and generalization, as our models can in many ways be understood as being, and/or containing, ideal types of various kinds, as these are "a one-sidedly focused synthesis of diffuse and 
discrete empirical phenomena into a unified abstract analytical construct which will never be discovered in this specific form" (Halkier 2011:790); Category zooming and "single variable generalization" involves "going into depth with the details and complexities in one single point of the study", instead of dealing with empirical wholes (Halkier 2011:792). This can often be part of what we do with our models, following the critical realist approach of attempting to close systems in order to see the effects of underlying causes and mechanisms. This also goes well with the use of contrastives, as it is "used to underline the contingency of types and categories" (Halkier 2011:792).

\section{EMPLOYING ABM IN MIXED METHODS RESEARCH}

There is a "baffling array of names and types of ways to conduct mixed methods research" available, and I briefly discussed some of the main typologies in part 2. As I focus on the implementation of ABM in the mix, I will not go into detail on the relationship between the qualitative and quantitative parts of the designs. One of the ways to approach the mixing of methods is to consider three designs: triangulation, explanatory/exploratory and embedded designs (Creswell 2011:278-9).

Figure 2: Triangulation

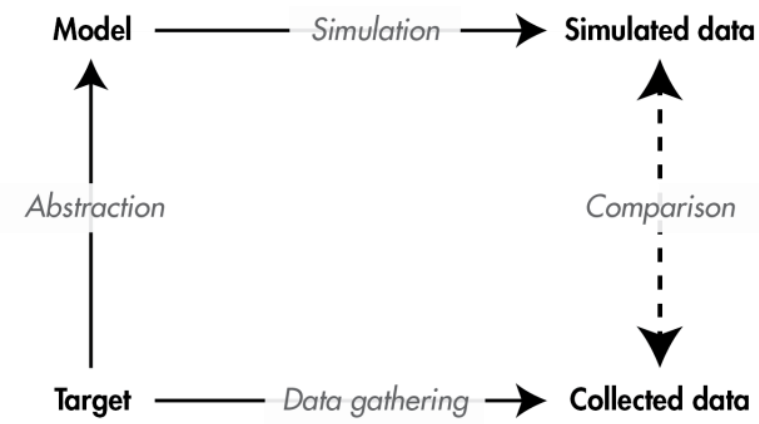

The approach shown in figure 2 involves the concurrent use of simulation of empirical data gathering, and the subsequent comparison of results. This is one way of understanding triangulation as approaching an issue from several angles. The simulated data is here used both as a "test" of our empirical results, and as a means of making sense of the phenomenon we have examined. The latter aspect is possible due to the transparent nature of the simulations we run - a transparency very seldom present in the real empirical phenomena. The crucial aspect in this approach is the quality of the abstractions carried out in the process of making our models.

Figure 3 shows an explanatory approach where we first gather empirical data, and then invoke $\mathrm{ABM}$ in order to explain what we found. This often involves using $\mathrm{ABM}$ as a means of understanding specific parts of the phenomenon in question. Which parts will be the subject of our ABM approach is often decided only after the initial empirical research is carried out, so this is usually a sequential design. 
Figure 3: Explanatory design

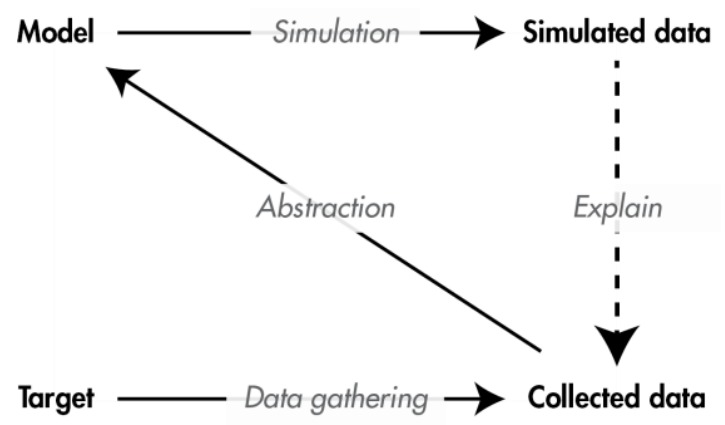

One clear advantage of this approach is that our models are informed by the empirical research done, which often leads to a higher degree of confidence in them.

Figure 4: Embedded design

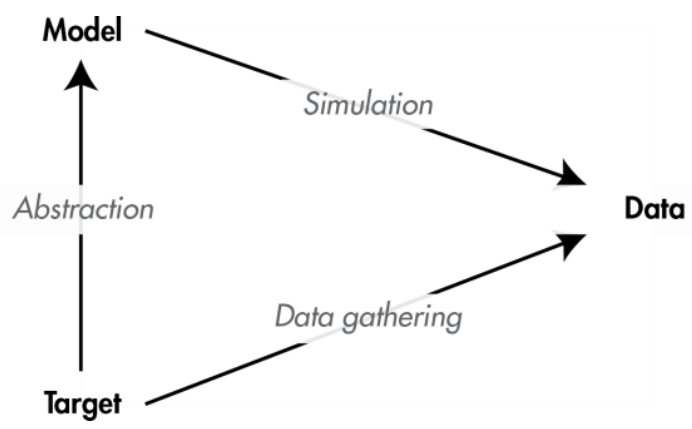

An approach less often used is the embedded design. Figure 4 shows an approach where we mix the data gathered from the two approaches (See Boero and Squazzoni, 2005, for a detailed account of the empirical "embeddedness" of ABM) (Creswell 2011:278-9). The role, or purpose, of $\mathrm{ABM}$ is here either theory development, theory testing, or validation of empirical results. One reason for not mixing our ABM results with empirical data is of course the obvious objections that are bound to arise with regards to conclusions based on a dataset involving artificial agents. We may, however, benefit from this approach if we use it to understand how our agents differ from (or are similar to) real agents through regression, analysis, etc. With reference to critical realism, one of the main reasons for the combination of $\mathrm{ABM}$ and other methods proposed in this paper is the existence of epistemological barriers as shown in figure 5. In critical realism, reality is conceived as consisting of three "layers", that are inherently different: the real, the actual and the empirical (Davidsen 2005:293). The mentioned barriers are caused by our lack of direct access to the real domain, where our targets of investigation might be.

If the target itself is an event or a phenomenon (i.e. at the actual or empirical level), these barriers might be overcome, but even in these cases the target phenomenon are caused by underlying mechanisms at the real level; if we wish to get to these mechanisms, the epistemological barrier must be circumvented in some way, and this is where ABM becomes useful. 
Figure 5: Epistemological barriers

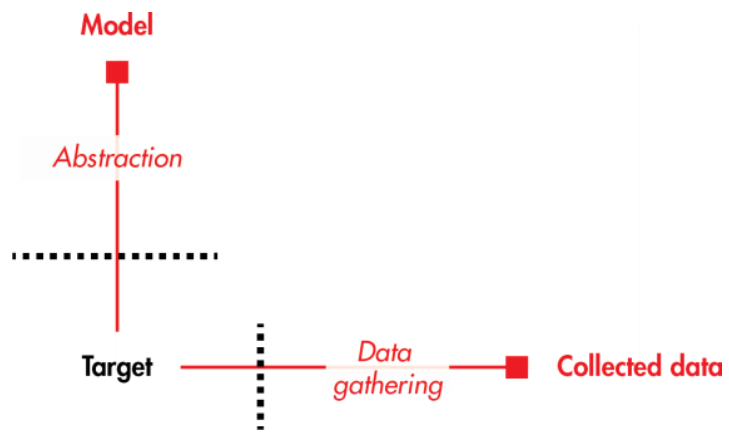

Figure 6 shows a situation in which our ability to conceptualize the real phenomenon is lacking; in this case we must approach the phenomena inductively, gathering what data we can, and from that point attempt to formulate theories and abstractions about the real phenomena. If we then run simulations and review our data, we may eventually illuminate the real phenomena in question, and reduce the problem of the barrier to understanding of the real phenomena.

Figure 6: Lack of conceptualization of the phenomena

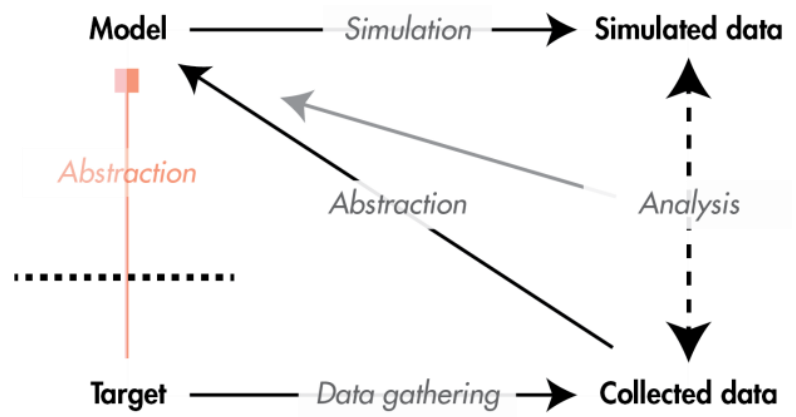

Figure 7: Lack of access to empirical data

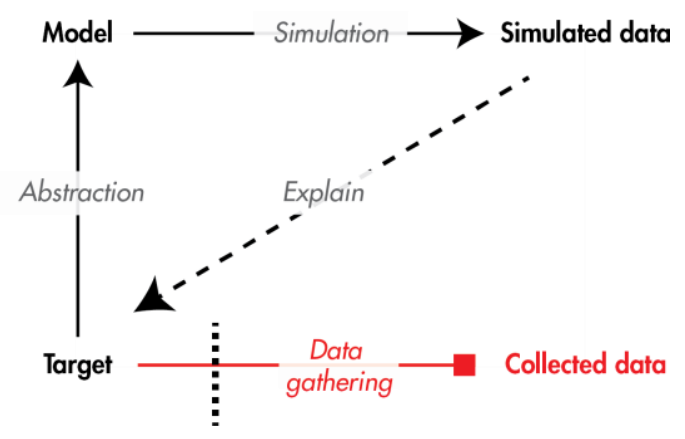


Figure 7 shows a different problem, where we have clear ideas about the phenomenon in question, but no access to empirical data. This is perhaps where ABM is most useful, as it lets us experiment with and test our theories, and when we gain a better understanding of the phenomenon, we might be able to imagine ways of gathering empirical data so that the problems of this epistemological barrier is also reduced.

Finally, I want to point out that retroduction or abduction (see section 3.1 for a detailed discussion of retroduction and abduction) can characterize most research here discussed. From the analysis of data (collected and/or simulated), we always get the opportunity to revise and improve our theories and models, create new hypotheses, and create or gather new data. A retroductive approach is shown in figure 8.

Figure 8: Mutually reinforcing approaches

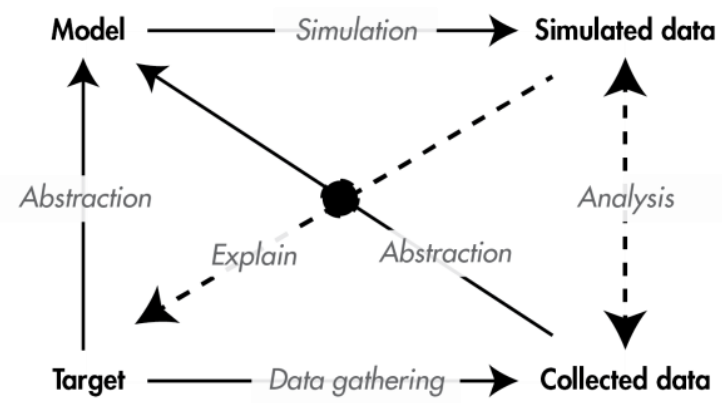

The models here outlined are not immediately related to the main models found in the typologies mentioned in 2 or the three "main kinds" given by Creswell and Plano Clark (2011:128). However, they mention some "specialized types", and the use of ABM to overcome epistemological barriers, or simply strengthen and improve "normal" types, may be considered a new specialized type of mixed methods research. This would be one of the "unusual blends" often found in practice, where we rarely see actual research conforming to the stylized typologies (Creswell 2011:279).

Perhaps the best approach would be to ignore the typologies focusing on the mix of quantitative and qualitative elements, and instead use the system of "five interactive dimensions" developed by Maxwell and Loomis (2003), dealing with "the purpose, the conceptual framework, the questions, the methods, and the issue of validity" (Creswell 2011:279). Conceptual framework involves the theories and assumptions that guide the research, and the research question informs us of what we will attempt to understand and what questions we will ask (Maxwell and Loomis 2003). Answering these questions will at times lead to the realization that there are epistemological barriers that may be overcome by the use of $\mathrm{ABM}$, or we might see that $\mathrm{ABM}$ will give us a stronger foundation for understanding phenomena where the epistemological barriers are not that prevalent.

\section{CONCLUSION}

Having examined mixed methods and ABM, it becomes clear that the possibility of employing $\mathrm{ABM}$ in mixed methods research can be expected to be a battle of definitions. The difficulty of classifying ABM within the methodologies of social science may be seen in 
several ways. Either we take it as a fundamental criticism of ABM, if we consider this difficulty a result of simulation not relating to fundamental principles and concepts in social science methodology. This would, I claim, be misguided, and an approach that would effectively preclude new methods from entering social science. The other interpretation is that the conventional classification of research as either qualitative or quantitative is fundamentally flawed, since it cannot accommodate an approach that has proven to be useful. I tend to regard the latter interpretation as the best way to proceed, and in doing so, I join Gobo (2008a) in calling for a move beyond quantitative or qualitative. We have, however, seen that we also have problems with properly placing ABM in his alternative classification. Still, it is a move in the right direction.

This being said, a fundamental critique of the conventional classification as here put forth has an unintended consequence: it may be perceived as a critique of the advent of mixed methods generally. This is because of the unfortunate explicit requirement of combining quantitative and qualitative research in most of the definitions of mixed methods. If the two concepts are flawed, schools basing itself so heavily on them are destined to run into problems.

What I have attempted to demonstrate is that ABM is an interesting new methodology that can fruitfully be employed in social science. I have also shown that the approach is completely dependent on the mix with other methods in order to evaluate and make sense of the results it provides. We may hope that there is room within mixed methods for approaches not easily put in one of the two traditional boxes, but if not, little is lost in calling the particular mix of methods here discussed for example triangulation or multi-method research.

\section{REFERENCES}

Archer, M. (1998) "Introduction: Realism in the social sciences". In M. Archer, R. Bhaskar, A. Collier, T. Lawson, and A. Norrie (Eds.), Critical Realism: Essential readings, Chapter 7. London: Routledge.

Axelrod, R. (2003) "Advancing the art of simulation in the social sciences-japanese journal for management information systems". Special Issue on Agent-Based Modeling, 12 (3).

Axelrod, R. M. (2006a) The complexity of cooperation: Agent-based models of competition and collaboration. New Delhi: New Age International Publishers.

Axelrod, R. M. (2006b) The evolution of cooperation. New York: Basic books.

Bhaskar, R. (1998a) "Facts and values: Theory and practice / reason and the dialectic of human emancipation / depth, rationality and change". In M. Archer, R. Bhaskar, A. Collier, T. Lawson, and A. Norrie (Eds.), Critical Realism: Essential readings, Chapter 17. London: Routledge.

Bhaskar, R. (1998b) "Societies". In M. Archer, R. Bhaskar, A. Collier, T. Lawson, and A. Norrie (Eds.), Critical Realism: Essential readings, Chapter 8. London: Routledge.

Bhaskar, R. (2009) Scientific realism and human emancipation. London: Routledge.

Boero, R. and Squazzoni, F. (2005) "Does empirical embeddedness matter? Methodological issues on agent-based models for analytical social science". Journal of Artificial Societies and Social Simulation, 8 (4).

Bryman, A. (2006) "Integrating quantitative and qualitative research: how is it done?" Qualitative research, 6 (1): 97-113.

Bryman, A. (2007) "Barriers to integrating quantitative and qualitative research". Journal of mixed methods research, 1 (1): 8-22.

Collier, A. (1998) "Explanation and emancipation". In M. Archer, R. Bhaskar, A. Collier, T. Lawson, and A. Norrie (Eds.), Critical Realism: Essential readings, Chapter 18. London: Routledge. 
Creswell, J. W. (2011) "Controversies in mixed methods research". The Sage handbook of qualitative research, 4: 269-84.

Creswell, J. W. and V. Plano Clark (2011) "Choosing a mixed methods design". Designing and conducting mixed methods research, 53-106.

Crookall, D. (2011). "Philosophy and simulation". Simulation \& Gaming, 42 (2), 146-150.

Davidsen, B.-I. (2005) "Arguing critical realism: The case of economics". Journal of Critical Realism, 4 (2): 291-314.

Davidsen, B.-I. (2010) "Towards a critical realist-inspired economic methodology". The Journal of Philosophical Economics, 3 (2): 74.

Dean, J. S.; G. J. Gumerman, J. M.; Epstein, R. L.; Axtell, A. C.; Swedlund, M. T. Parker, and S. McCarroll (2000) "Understanding anasazi culture change through agent-based modeling". Dynamics in human and primate societies: Agent-based modeling of social and spatial processes, 179-205.

Epstein, J. M. and R. Axtell (1996) Growing artificial societies: social science from the bottom up. Washington: Brookings Institution Press.

Gilbert, N. and K. Troitzsch (2005) Simulation for the social scientist. London: McGraw- Hill Education (UK).

Gobo, G. (2008a) Doing ethnography. London: Sage.

Gobo, G. (2008b) "Re-conceptualizing generalization: Old issues in a new frame". The SAGE handbook of social research methods, 193-213.

Goldstein, J. (1999) "Emergence as a construct: History and issues". Emergence, 1 (1): 49-72.

Greene, J. C.; Caracelli, V. J. and Graham, W. F. (1989) "Toward a conceptual framework for mixedmethod evaluation designs". Educational evaluation and policy analysis, 11 (3): 255-274.

Halkier, B. (2011). "Methodological practicalities in analytical generalization". Qualitative Inquiry, 17 (9): 787-797.

Henrickson, L. and McKelvey, B. (2002) "Foundations of "new" social science: Institutional legitimacy from philosophy, complexity science, postmodernism, and agent-based modeling". Proceedings of the National Academy of Sciences 99 (suppl 3), 7288- 7295.

Heyvaert, M.; Maes, B. and Onghena, P. (2013) "Mixed methods research synthesis: definition, framework, and potential". Quality \& Quantity, 47 (2): 659-676.

Hughes, R. I. G. (1999) "The ising model, computer simulation, and universal physics". In M. Archer, R. Bhaskar, A. Collier, T. Lawson, and A. Norrie (Eds.), Models as Mediators: Perspectives on Natural and Social Science, Chapter 5. Cambridge: Cambridge University Press.

Johnson, R. B. and Onwuegbuzie, A. J. (2004) "Mixed methods research: A research paradigm whose time has come". Educational Researcher, 33 (7): 14-26.

Johnson, R. B.; Onwuegbuzie, A. J. and Turner, L. A. (2007) "Toward a definition of mixed methods research". Journal of mixed methods research, 1 (2): 112-133.

Lawson, T. (1998) "Economic science without experimentation". In M. Archer; Bhaskar, R.; Collier, A.; Lawson, T. and Norrie, A. (Eds.), Critical Realism: Essential readings, Chapter 6. London: Routledge.

Leech, N. L. and Onwuegbuzie, A. J. (2009) "A typology of mixed methods research designs". Quality \& quantity, 43 (2): 265-275.

Levin, S. A. (1998) "Ecosystems and the biosphere as complex adaptive systems". Ecosystems, 1 (5): 431-436.

Lieberson, S. (1991) "Small n's and big conclusions: an examination of the reasoning in comparative studies based on a small number of cases". Social forces, 70 (2): 307-320.

Maxwell, J. A. and Loomis, D. M. (2003) "Mixed methods design: An alternative approach". Handbook of mixed methods in social and behavioral research, 1, 241-272.

Miller, K. D. (2014) "Agent-based modeling and organization studies: A critical realist perspective". Organization Studies, 0170840614556921.

Mingers, J. (2006) "Philosophical foundations: Critical realism". Realising Systems Thinking: Knowledge and Action in Management Science, 11-31.

Morgan, D. L. (2007) "Paradigms lost and pragmatism regained methodological impli- cations of combining qualitative and quantitative methods". Journal of mixed methods research, 1 (1): 48-76. 
Onwuegbuzie, A. J. and Collins, K. M. (2007) “A typology of mixed methods sampling designs in social science research". The qualitative report, 12 (2), 281-316.

Outhwaite, W. (1998) "Realism and social science". In M. Archer, R. Bhaskar, A. Collier, T. Lawson, and A. Norrie (Eds.), Critical Realism: Essential readings, Chapter 10. London: Routledge.

Peirce, C. S. (1998) The essential Peirce: Selected philosophical writings (Vol. 2). Bloomington: Indiana University Press.

Railsback, S. F. and V. Grimm (2011) Agent-based and individual-based modeling: a practical introduction. Princeton: Princeton university press.

Sawyer, R. K. (2004) "The mechanisms of emergence". Philosophy of the Social Sciences, 34 (2), 260282.

Sieber, S. D. (1973) "The integration of fieldwork and survey methods". American journal of sociology, 1335-1359.

Simon, H. A. (1996) The sciences of the artificial. Cambridge: MIT Press.

Symonds, J. E. and S. Gorard (2008) "The death of mixed methods: research labels and their casualties". In The British Educational Research Association Annual Conference. Heriot Watt University. Edimburgh, 3-6 November, in https://goo.gl/XuZrVZ

Teddlie, C. and A. Tashakkori (2006) "A general typology of research designs featuring mixed methods". Research in the Schools, 13 (1): 12-28.

Williams, M. (2000) “Interpretivism and generalization”. Sociology, 34 (2): 209-224.

Winsberg, E. (2003) "Simulated experiments: Methodology for a virtual world". Philosophy of science, 70 (1): $105-125$.

\section{Breve currículo:}

\section{Henrik Skaug Satra}

Associate professor at Østfold University College, master degree in 2009 (Political science, University of Oslo). Research interests are centered on the search for robust and minimalist justifications of the state, and the study of writings about Thomas Hobbes and the other classical social contract theorists. Besides classical political theory, interested in environmental ethics, game theory, and agent-based modeling. Currently enrolled in the PhD program at the University of Oslo. 